\title{
Novel cell culture model for prevention of carcinogenic risk in familial adenomatous polyposis syndrome
}

\author{
NITIN TELANG ${ }^{1}$ and MEENA KATDARE ${ }^{2}$ \\ ${ }^{1}$ Cancer Prevention Research, Palindrome Liaisons, Montvale, NJ; ${ }^{2}$ Carcinogenesis and Chemoprevention Laboratory, \\ Department of Surgery, Weill Cornell Medical College, New York, NY, USA
}

Received December 30, 2008; Accepted February 9, 2009

DOI: 10.3892/or_00000318

\begin{abstract}
Clinical familial adenomatous polyposis (FAP) syndrome represents a high risk pre-invasive precursor for colon cancer, and is characterized by germ line mutation in the adenomatous polyposis coli (APC) tumor suppressor gene. Cellular models with relevant genetic and biological characteristics should provide important mechanistic leads for predisposition and preventive intervention. Cloned colon epithelial cell line from the $\mathrm{Apc}^{850 \mathrm{Min}} /+$ mouse represented a model for FAP. Cell cycle progression, cellular apoptosis and anchorage-independent growth represented the biomarkers for carcinogenic risk. The Apc mutant $850^{\mathrm{Min}} \mathrm{COL}-\mathrm{Cl}_{1}$ cells exhibited decreased $\mathrm{G}_{0} / \mathrm{G}_{1}: \mathrm{S}+\mathrm{G}_{2} / \mathrm{M}$ ratio, increased $\mathrm{S}+\mathrm{G}_{2} / \mathrm{M}$ : $\mathrm{subG}_{0}$ ratio, and increased anchorage-independent colony formation, indicating loss of homeostatic growth control and gain of anchorage-independent growth. Growth of these cells in serum-depleted medium was promoted by mitogenic insulin and epidermal growth factor, and inhibited by antimitogenic transforming growth factor- $\beta_{1}$ and dexamethasone. Treatment with low dose combinations of synthetic enzyme inhibitor difluoro methylornithine (DFMO), synthetic nonsteroidal anti-inflammatory drug sulindac (SUL), and naturally occurring epigallocatechin gallate (EGCG), and eicosapentaenoic acid (EPA) produced cytostatic growth arrest and inhibited anchorage-independent colony formation. These data identify a novel cell culture model and validate a mechanism-based approach to prioritize combinations of effective chemopreventive compounds for prevention/therapy of colon cancer.
\end{abstract}

Correspondence to: Dr Nitin Telang, Palindrome Liaisons, 10 Rolling Ridge Road, Suite B, Montvale, NJ 07645-1559, USA E-mail: entitytoo@cs.com

Dr Meena Katdare, Department of Surgery, Weill Cornell Medical College, 1300 York Avenue, Box-287, New York, NY 10065, USA E-mail: msk2004@med.cornell.edu

Key words: colon epithelial cells, Apc mutation, carcinogenic risk, chemoprevention

\section{Introduction}

Colon cancer represents one of the leading causes of mortality in the Western countries. The American Cancer Society estimates a $21 \%$ newly diagnosed colon cancer cases and $15 \%$ cancer related deaths in 2008 (1). These estimates emphasize an urgent need for identification of specific and sensitive biomarkers for detection of cancer risk and for effective preventive/therapeutic interventional strategies $(2,3)$.

Several elegant seminal observations have provided support to the concept that early-occurring molecular/genetic events such as germ-line/somatic mutations in the adenomatous polyposis coli (APC) tumor suppressor gene predispose the target colonic epithelium for the risk of familial/sporadic carcinogenesis, and in the multi-step process of colon carcinogenesis, Apc mutation represents a primary genetic defect resulting in the familial adenomatous polyposis (FAP) syndrome, a high risk precursor for colon cancer (2-4).

Chemoprevention of epithelial organ-site carcinogenesis using synthetic pharmacological agents, naturally-occurring dietary phytochemicals, or low-dose combinations thereof to inhibit, reduce or delay pre-invasive lesions represents a promising strategy $(2,3,5)$. Thus, several studies on preclinical animal models for the FAP syndrome have provided a strong proof of principle evidence supporting a clinically relevant translational potential for prevention of colon cancer (6-9).

Existing animal models, however, exhibit carcinogenesis predominantly in the small intestine, rather than in the colon, while the FAP syndrome is characterized by the presence of colorectal adenomas (10-12).

Cell culture models from appropriate target organ site expressing clinically relevant genetic defects and exhibiting quantifiable risk for carcinogenesis promise to provide a rapid alternative approach that complements the traditional longterm in vivo animal studies (13-16). Such cell culture studies should facilitate identification of critical molecular mechanisms for carcinogenic risk as well as for validating and prioritizing efficacious preventive intervention in long-term animal studies. Positive outcome from these studies may represent clinically translatable proof of principle for future clinical trials.

Our previous studies have documented development and validation of cell culture models for genetically predisposed early onset colon cancer (13-15). Experiments designed in the present study were focused on developing a cell culture model 
from the well established $\mathrm{Apc}^{\mathrm{Min}} /+$ mouse, to characterize the model for carcinogenic risk and to validate the developed model as a mechanism-based screen for the efficacy of low dose combinations of mechanistically distinct chemopreventive agents. Here we provide evidence that Apc mutant colon epithelial cells exhibit loss of homeostatic growth control and gain of carcinogenic risk, and that these perturbations are modulated in response to low dose combinations of select synthetic and natural compounds.

\section{Materials and methods}

Cell lines. The wild-type $\mathrm{Apc}^{+/+} \mathrm{C} 57 \mathrm{COL}$ cell line (source: descending colon of C57BL/6J mouse) and the Apc mutant $850^{\text {Min }} \mathrm{COL}-\mathrm{Cl}_{1}$ cell line (source: descending colon of $\mathrm{Apc}^{850 \mathrm{Min} /+}$ mouse) were cultured in DME/F12 medium supplemented with heat inactivated $10 \%$ fetal calf serum, $0.24 \mathrm{IU} / \mathrm{ml}(10 \mu \mathrm{g} / \mathrm{ml})$ insulin and $1 \mu \mathrm{M}$ dexamethasone. The culture medium also contained the antibiotic mixture (100 IU/ $100 \mu \mathrm{g} / \mathrm{ml}$ penicillin/streptomycin $+50 \mu \mathrm{g} / \mathrm{ml}$ fungizone + $50 \mu \mathrm{g} / \mathrm{ml}$ gentamycin). Routinely, the stock cultures were maintained in humidified atmosphere of $95 \%$ air: $5 \% \mathrm{CO}_{2}$ at $37^{\circ} \mathrm{C}$, fed every $48 \mathrm{~h}$ and sub-cultured by $1: 10$ split at $70-80 \%$ confluency $(13,14)$. The Apc mutant cell cline was clonally selected from a single anchorage-independent colony formed in $0.33 \%$ agar (16).

Population doubling time and growth kinetics. The status of these quantitative biomarkers was determined following previously published methods (14-16). The data were expressed as the mean of five time points during the exponential growth phase of $120 \mathrm{~h}$, and as the number of viable cells at day 5 post-seeding of $1.0 \times 10^{5}$ cells, respectively.

Cell cycle progression and cellular apoptosis. These biomarkers were quantified using the data obtained from flow cytometry according to the previously published methods (14). The data were expressed as $\mathrm{G}_{0} / \mathrm{G}_{1}: \mathrm{S}+\mathrm{G}_{2} / \mathrm{M}$ and $\mathrm{S}+\mathrm{G}_{2} / \mathrm{M}$ : $\mathrm{subG}_{0}$ ratios, respectively.

Growth adaptation of cells in serum-depleted medium. The cell lines routinely grown in the medium supplemented with $10 \%$ serum were sequentially cultured in media supplemented with $7.5 \%, 5.0 \%, 2.5 \%$ and $1.0 \%$ serum. Cells surviving in the medium containing $1.0 \%$ serum were subsequently adapted for growth in the medium containing $0.01 \%$ serum for at least 5 passages, prior to use in the experiments.

Anchorage-independent colony formation. This assay was performed following previously published methods (16). Data were expressed as the number of colonies at day 14 postseeding of 100 cells.

Chemopreventive test compounds. The selective ornithine decarboxylase inhibitor difluoro methylornithine (DFMO), non-steroidal anti-inflammatory drug sulindac (SUL) and natural phytochemicals, epigallocatechin gallate (EGCG), and omega-3 polyunsaturated fatty acid eicosa pentaenoic acid (EPA) were obtained from the Sigma Chemical Co. The stock solutions of each test compound $(100 \mathrm{mM})$ was made
Table I. Status of biomarker expression in colon epithelial cell lines.

\begin{tabular}{|c|c|c|}
\hline \multirow[t]{2}{*}{ Biomarker } & \multicolumn{2}{|c|}{ Cell line } \\
\hline & C57 COL & $850^{\operatorname{Min}} \mathrm{COL}-\mathrm{Cl}_{1}$ \\
\hline Population doubling ${ }^{\mathrm{a}}$ & $34 \mathrm{~h}$ & $12 \mathrm{~h}$ \\
\hline Viable cell number $\left(\mathrm{x} 10^{5}\right)^{\mathrm{a}}$ & $7.7 \pm 0.8$ & $64.6 \pm 4.6$ \\
\hline $\mathrm{G}_{0} / \mathrm{G}_{1}: \mathrm{S}+\mathrm{G}_{2} / \mathrm{M}(\mathrm{Q}: \text { P ratio })^{\mathrm{b}}$ & $3.1 \pm 0.5$ & $0.6 \pm 0.5$ \\
\hline $\mathrm{S}+\mathrm{G}_{2} / \mathrm{M}: \mathrm{subG}_{0}(\mathrm{P}: \text { A ratio })^{\mathrm{b}}$ & $5.7 \pm 0.3$ & $78.0 \pm 6.2$ \\
\hline \multicolumn{3}{|l|}{$\begin{array}{l}\text { Anchorage-independent } \\
\text { colony formation }^{c}\end{array}$} \\
\hline Passage no. 8 & $0 / 18$ & $9 / 18$ \\
\hline Mean colony no. & - & $8.4 \pm 1.1$ \\
\hline Passage no. 25 & $0 / 18$ & $18 / 18$ \\
\hline Mean colony no. & - & $25.7 \pm 3.0$ \\
\hline
\end{tabular}

${ }^{a}$ Determined during the exponential growth phase; ${ }^{b}$ Determined by

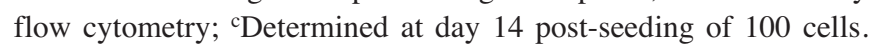
Mean \pm SD, $n=18$.

up in $100 \%$ ethanol and was serially diluted in the culture medium to obtain $5 \log \mu \mathrm{M}$ concentrations of $0.01,0.1,1$, 10 , and $100 \mu \mathrm{M}$ to be used for the initial dose response experiments. These data identified the minimum effective concentrations for each test compound for the combination treatment schedule. The primary dose response data were also used to calculate $\mathrm{IC}_{50}$ values for each test compound.

Statistical analysis. The experiments on growth modulation of serum-depleted cells and those on cytostatic growth arrest were performed in duplicate $(n=3$ per treatment group, per experiment). The experiments on anchorage-independent colony formation were performed in triplicate $(n=6$ per treatment group, per experiment). The data generated from these experiments were analyzed for the statistical significance between the control and the experimental groups by appropriate statistical tests using the StatView 4.01 software. p-values of $<0.05$ were considered significant.

\section{Results}

Apc mutant cells exhibit aberrant proliferation and enhanced risk for carcinogenesis. The experiment presented in Table I was designed to compare the status of cell proliferation and risk for carcinogenesis in the wild-type $\mathrm{Apc}^{+/+} \mathrm{C} 57 \mathrm{COL}$ and Apc mutant $850^{\mathrm{Min}} \mathrm{COL}-\mathrm{CL}_{1}$ cells. Relative to the wild-type Apc cells the Apc mutant cells exhibited a $64.7 \%$ decrease in the population doubling time and a 7.4-fold increase in the saturation density. These data on aberrant proliferation were further confirmed by $80.6 \%$ decrease in the $G_{0} / G_{1}: S+G_{2} / M$ ratio and 12.7 -fold increase in the $\mathrm{S}+\mathrm{G}_{2} / \mathrm{M}$ : subG $\mathrm{G}_{0}$ ratio. 
Table II. Growth modulation of Apc mutant $850^{\mathrm{Min}} \mathrm{COL}-\mathrm{Cl}_{1}$ cells in serum-depleted culture medium.

\begin{tabular}{lcc}
\hline Medium additive & Concentration & $\begin{array}{c}\text { Viable cell count } \\
\left(\times 10^{5}\right)^{\mathrm{a}}\end{array}$ \\
\hline Serum & $0.01 \%$ & $12.2 \pm 1.2^{\mathrm{b}}$ \\
Serum+INS & $10 \mu \mathrm{g} / \mathrm{ml}$ & $29.4 \pm 1.6^{\mathrm{c}}$ \\
Serum+EGF & $10 \mathrm{ng} / \mathrm{ml}$ & $32.7 \pm 1.7^{\mathrm{c}}$ \\
Serum+DEX & $2 \mu \mathrm{M}$ & $11.3 \pm 1.6$ \\
Serum+TGFß & $3 \mathrm{ng} / \mathrm{ml}$ & $3.8 \pm 1.5^{\mathrm{d}}$ \\
Serum+INS+EGF & & $34.0 \pm 0.8^{\mathrm{c}}$ \\
\hline
\end{tabular}

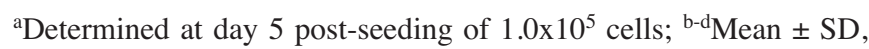
$\mathrm{n}=6$ per treatment group; ${ }^{\mathrm{b}, \mathrm{c}} \mathrm{p}=0.03 ;{ }^{\mathrm{b}-\mathrm{d}} \mathrm{p}=0.02$.

Table III. Response of Apc mutant $850^{\mathrm{Min}} \mathrm{COL}-\mathrm{Cl}_{1}$ cells to chemopreventive test compounds.

\begin{tabular}{lcc}
\hline & \multicolumn{2}{c}{$\mathrm{IC}_{50}(\mu \mathrm{M})$} \\
\cline { 2 - 3 } $\begin{array}{l}\text { Test } \\
\text { compound }\end{array}$ & $\begin{array}{c}\text { Viable cell } \\
\text { count }^{\mathrm{a}}\end{array}$ & $\begin{array}{c}\text { Anchorage-independent } \\
\text { growth }^{\mathrm{b}}\end{array}$ \\
\hline SUL & 38.1 & 7.9 \\
DFMO & 35.1 & 6.3 \\
EGCG & 0.7 & 0.6 \\
EPA & 17.8 & 7.8
\end{tabular}

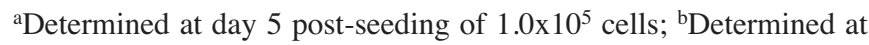
day 14 post-seeding of 100 cells.

To evaluate the carcinogenic risk, anchorage-independent colony formation was used as an in vitro surrogate end point biomarker. The early passage (p8) and the late passage (p25) Apc mutant cells exhibited a 50\% and a $100 \%$ incidence of anchorage-independent colonies, with an average colony count of $8.4 \pm 1.1$ and $25.7 \pm 3.0$, respectively. In contrast, the wild-type Apc cells lacked the expression of this biomarker.

Select hormones and growth factors modulate the growth of Apc mutant cells in serum-depleted medium. The experiment presented in Table II was designed to examine the effects of hormones and growth factors on Apc mutant cells. Insulin and epidermal growth factor independently as well as in combination exhibited a 1.4-, 1.7- and 1.8-fold increase in the number of viable cells respectively, relative to those observed in cultures grown in the presence of $0.01 \%$ serum. In contrast, dexamethasone and transforming growth factor- $\beta_{1}$ (TGF- $\left.\beta_{1}\right)$, as independent agents, exhibited a 7.4-, and a $68.8 \%$ decrease in the number of viable cells, respectively.

Table IV . Cytostatic growth arrest of Apc mutant $850^{\mathrm{Min}}$ COL$\mathrm{Cl}_{1}$ cells by chemopreventive test compounds.

Test

compound

\begin{tabular}{lrrc}
\hline Solvent control & $0.01 \%$ & $66.6 \pm 4.6$ & - \\
SUL & $10 \mu \mathrm{M}$ & $59.1 \pm 4.1$ & 11.3 \\
DFMO & $10 \mu \mathrm{M}$ & $57.7 \pm 4.0$ & 13.4 \\
EGCG & $0.1 \mu \mathrm{M}$ & $59.9 \pm 4.1$ & 10.1 \\
EPA & $5 \mu \mathrm{M}$ & $56.7 \pm 2.4$ & 14.9 \\
SUL+DFMO & $10+10 \mu \mathrm{M}$ & $36.4 \pm 2.5$ & 45.3 \\
EGCG+DFMO & $0.1+10 \mu \mathrm{M}$ & $34.3 \pm 1.6$ & 48.5 \\
EPA+DFMO & $5+10 \mu \mathrm{M}$ & $37.5 \pm 1.5$ & 43.7 \\
\hline
\end{tabular}

aDetermined at day 5 post-seeding of $1.0 \times 10^{5}$ cells. Mean $\pm \mathrm{SD}, \mathrm{n}=6$ per treatment group. ${ }^{\mathrm{b}} \mathrm{SUL}+\mathrm{DFMO}$ versus $\mathrm{SUL}, \mathrm{DFMO}, \mathrm{p}=0.02$; EGCG+DFMO versus EGCG, DFMO, $\mathrm{p}=0.01$; $\mathrm{EPA}+\mathrm{DFMO}$ versus EPA, DFMO, $\mathrm{p}=0.02$.

Combination of chemopreventive test compounds induces cytostatic growth arrest in Apc mutant cells. The data presented in Table III compares the $\mathrm{IC}_{50}$ values of individual test compounds extrapolated from the $5 \log \mu \mathrm{M}$ dose range. These values compared favorably with pharmacologically achievable concentrations in the plasma of $\mathrm{Apc}^{\mathrm{Min}} /+$ mouse.

The experiment presented in Table IV was designed to examine whether low dose combinations of mechanistically distinct chemopreventive test compounds affect the growth of Apc mutant cells. The data generated from these experiments clearly demonstrated that relative to the individual compounds SUL+DFMO, EGCG+DFMO and EPA+DFMO exhibited enhanced efficacy for growth arrest. Thus, SUL+DFMO produced 2.4- to 3.0-fold higher efficacy $(\mathrm{p}=0.02)$ than SUL or DFMO alone, EGCG+DFMO produced 2.6- to 3.8-fold higher efficacy $(p=0.01)$ than EGCG or DFMO alone, and EPA+DFMO produced 1.9- to 2.3-fold higher efficacy $(\mathrm{p}=0.02)$ for growth arrest than EPA or DFMO alone.

Combination of chemopreventive test compounds inhibits carcinogenic risk in Apc mutant cells. The experiments presented in Table $\mathrm{V}$ were designed to examine whether the combination of chemopreventive test compounds confers superior efficacy for inhibition of carcinogenic risk. These experiments utilized the anchorage-independent colony formation assay as the quantitative endpoint. The data generated from these experiments demonstrated that combinations of SUL+DFMO, EGCG+DFMO and EPA+DFMO exhibited higher efficacy than these compounds used as single agents. Thus, SUL+DFMO produced 2.5- to 4.1-fold higher efficacy $(\mathrm{p}=0.01)$ than SUL or DFMO alone, EGCG+DFMO produced 2.9- to 4.5-fold higher efficacy ( $\mathrm{p}=0.01$ ) than EGCG or DFMO alone, and EPA+DFMO produced 2.7- to 3.8-fold higher efficacy $(p=0.01)$ than EPA or DFMO alone for inhibition in the number of anchorage-independent colonies. 
Table V. Inhibition of anchorage-independent colony formation in Apc mutant $850^{\mathrm{Min}} \mathrm{COL}-\mathrm{Cl}_{1}$ cells by chemopreventive test compounds.

\begin{tabular}{lrcc}
\hline $\begin{array}{l}\text { Test } \\
\text { compound }\end{array}$ & Concentration & $\begin{array}{c}\text { No. of anchorage- } \\
\text { independent } \\
\text { colonies }^{\mathrm{a}, \mathrm{b}}\end{array}$ & $\begin{array}{c}\text { Inhibition } \\
(\% \text { control })\end{array}$ \\
\hline Solvent control & $0.01 \%$ & $25.4 \pm 3.0$ & - \\
SUL & $2 \mu \mathrm{M}$ & $22.9 \pm 2.7$ & 9.8 \\
DFMO & $2 \mu \mathrm{M}$ & $21.8 \pm 2.7$ & 14.2 \\
EGCG & $0.2 \mu \mathrm{M}$ & $22.8 \pm 2.6$ & 10.2 \\
EPA & $1 \mu \mathrm{M}$ & $22.6 \pm 2.6$ & 11.0 \\
SUL+DFMO & $2+2 \mu \mathrm{M}$ & $12.8 \pm 1.3$ & 49.6 \\
EGCG+DFMO & $0.2+2 \mu \mathrm{M}$ & $11.2 \pm 1.3$ & 55.9 \\
EPA+DFMO & $1+2 \mu \mathrm{M}$ & $12.1 \pm 1.3$ & 52.4 \\
\hline
\end{tabular}

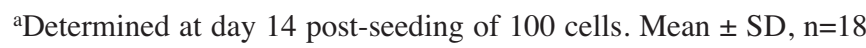
per treatment group. ${ }^{b} \mathrm{SUL}+\mathrm{DFMO}$ versus SUL, DFMO, $\mathrm{p}=0.01$; EGCG+DFMO versus EGCG, DFMO, $\mathrm{p}=0.01 ; \mathrm{EPA}+\mathrm{DFMO}$ versus EPA, DFMO, $\mathrm{p}=0.01$.

\section{Discussion}

In the multi-step colon carcinogenesis of genetically predisposed FAP, adenoma is considered as a pre-invasive precursor lesion that has a germ line mutation in the Apc tumor suppressor gene (4). The genetically predisposed animal models for FAP syndrome exhibit high incidence of adenoma predominantly in the small intestine, rather than in the colon (10-12). However, genetic manipulation of the Apc mutant mouse through crosses with BubR1 $1^{+/}(17)$, Smad-3 (18), ER- $\alpha^{+/}$, ER- $\beta^{+/-}$and ER- $\beta^{-/-}(19)$, Fabpl-Cre/Apc-lox-p conditional truncated Apc mice (20) and Muc2 (21) has been demonstrated to specifically accelerate colon carcinogenesis. Thus, reliable colon cell culture model with Apc mutation and quantifiable carcinogenic risk should provide an alternative approach complementing the existing preclinical genetically predisposed animal models.

The data generated from the present study unequivocally demonstrate that Apc mutant epithelial cells derived from histologically normal descending colon of $\mathrm{Apc}^{\mathrm{Min}} /+$ mouse exhibit loss of homeostatic growth control as evidenced by aberrant proliferation, altered cell cycle progression and downregulated cellular apoptosis, and gain of carcinogenic risk as evidenced by high incidence and frequency of anchorageindependent colonies. Previously published studies on oncogene transfected mammary epithelial cells $(16,22)$, and also on Apc ${ }^{1638 \mathrm{~N}}$ colon epithelial cells (23), have demonstrated that these 'initiated' cells progress to anchorage-independent growth in vitro, and upon in vivo transplantation, produce rapidly growing tumors at the transplant sites. This published evidence taken together with the present data indicates that Apc mutant $850^{\mathrm{Min}} \mathrm{COL}-\mathrm{Cl}_{1}$ cells are at increased risk for carcinogenesis, and that anchorage independent colony formation represents a specific and sensitive surrogate end point biomarker for carcinogenic transformation.

Select polypeptide and steroid hormones and peptide growth factors are known to play important modulatory roles in the progression of colon cancer $(24,25)$. It is therefore, interesting to note that pro-mitogenic INS and EGF promoted, while anti-mitogenic TGF- $\beta_{1}$ inhibited the growth of Apc mutant cells. These data are also consistent with our previously published study on myc transfected mammary epithelial cells where these growth factors modulated the growth in a similar manner (16).

Effective adaptation of $850^{\text {Min }} \mathrm{COL}-\mathrm{Cl}_{1}$ cells to grow in chemically-defined serum depleted medium that contains ineffective low concentrations of growth factors/hormones such as EGF, TGF- $\beta_{1}$, insulin and corticosteroids, and persistent cellular responsiveness to these agents provides a valuable approach to examine functional interactions of select growth factors/hormones on colon cell proliferation, apoptosis, cyto-differentiation and carcinogenesis. These outcomes will complement in vivo investigations on genetically engineered mouse models such as BubR1/Apc ${ }^{\mathrm{Min}}$ (17), Smad-3/Apc ${ }^{\mathrm{Min}}$ (18), ER-ß/Apc ${ }^{\mathrm{Min}}$ (19), and Muc2/Apc (21) that exhibit increased incidence of colon carcinogenesis. Taken together, these aspects are expected to strengthen the concept that genetically engineered mice represent valuable predictive models for human colon carcinogenesis and chemoprevention (26-28).

Chronic high dose single agent therapy using synthetic pharmacological agents has been followed in FAP patients. However, these interventional strategies are associated with adverse toxic side effects that compromise patient compliance (29-32).

Strong proof of principle evidence in preclinical laboratory studies on combinatorial prevention with NSAID+polyamine synthesis inhibitor (7), selective COX-2 inhibitor+Atorvastatin (8), and NSAID+EGFR inhibitor (9) and selective COX-2 inhibitor+omega-3 fatty acid (33) have shown promise to enhance preventive efficacy and reduce systemic toxicity. More recently, this proof of principle preclinical evidence has been extended and confirmed in a clinical trial with SUL+DFMO on sporadic colon cancer (34). Furthermore, minimally toxic natural dietary components may also modulate the efficacy of toxic chemotherapeutic drugs (35). On the mechanistic level, DFMO functions as a selective inhibitor of ornithine decarboxylase which is an established early response gene and a rate limiting enzyme for the biosynthesis of polyamines $(30,31)$, SUL is a non-selective cyclooxygenase inhibitor (34), EGCG is demonstrated to affect EGF signaling (36), while EPA functions as an inhibitor of lipoxygenase, a critical enzyme for production of leukotrienes (33). All of these targets are known to play important roles in colon carcinogenesis. It will therefore be of considerable interest to examine additive or synergistic modulation in the status of these specific molecular targets that may be responsible for the enhanced efficacy of SUL+DFMO, EGCG+DFMO and $\mathrm{EPA}+\mathrm{DFMO}$ combinations. In this context it is noteworthy that the present data demonstrating enhanced efficacy of SUL+DFMO, EGCG+DFMO and EPA+DFMO for induction of cytostatic growth arrest and for inhibition of carcinogenic risk in Apc mutant cells extend and confirm our previously 
published data generated by different combinations on other cell culture models $(14,15,23)$. In a recent study a novel miRNA based mechanism for positive regulation of APC has been proposed from the data generated from colon carcinoma cell lines as well as from limited patient samples (37). Particularly significant aspect in the present context is the correlation of miR-135 expression and APC expression with the disease progression in the clinical samples. Thus, the present cell culture model for the FAP syndrome that exhibits a correlation of cellular biomarkers for carcinogenic risk offers a scientifically robust approach to confirm and extend the identification of miR-135 as a novel mechanistic molecular biomarker for carcinogenic risk as well for its modulation.

Overall, the outcome from present study validates a novel mechanism based approach to prioritize efficacious combinations for future animal experiments and for subsequent clinical trials on prevention/therapy of colon cancer.

\section{Acknowledgements}

The authors wish to thank Milan Zvanovec and Tonye Briggs for their technical participation. This research was supported in part by National Cancer Institute grants CA29502-S1, CN 75029-63 (N.T.), and CA29502-20, RO1 CA122394 (M.K.), and the funds from Irving Weinstein Foundation (N.T. and M.K.).

\section{References}

1. Jemal AR, Segal R, Ward E, et al: Cancer statistics. Cancer J Clin 58: 71-96, 2008.

2. Kelloff GJ, Lippman SM, Dannenberg AJ, et al: Progress in chemoprevention drug development: the promise of molecular biomarkers for prevention of intraepithelial neoplasia and cancer, a plan to move forward. Clin Cancer Res 22: 3661-3697, 2006.

3. O'Shauhnessy JA, Kelloff GJ, Gordon GB, et al: Treatment and prevention of intraepithelial neoplasia: an important target for accelerated new agent development. Clin Cancer Res 8: 314-346, 2002.

4. Fearon ER and Vogelstein B: A genetic model for colorectal tumorigenesis. Cell 61: 759-767, 1990.

5. Hong WK and Sporn MB: Advances in chemoprevention of cancer. Science 278: 1073-1077, 1997.

6. Jacoby RF, Siebert K, Cole CE, et al: The cyclooxygenase inhibitor celecoxib is a potent preventive and therapeutic agent in the $\mathrm{Apc}^{\mathrm{Min}}$ mouse model of familial adenomatous polyposis. Cancer Res 60: 5040-5044, 2000.

7. Jacoby RF, Cole CE, Tutsch K, et al: Chemopreventive efficacy of combined Piroxicam and Difluoro methylornithine treatment on Apc mutant mouse adenoma and selective toxicity against Apc mutant embryos. Cancer Res 60: 1864-1870, 2000

8. Swamy MV, Patlolla JMR, Steele VE, et al: Chemoprevention of familial adenomatous polyposis by low doses of Atorvastatin and Celecoxib given individually and in combination to $\mathrm{Apc}^{\mathrm{Min}}$ mice. Cancer Res 66: 7370-7377, 2006.

9. Torrance CJ, Jackson PE, Montgomery E, et al: Combinatorial chemoprevention of intestinal neoplasia. Nat Med 6: 1024-1028, 2000.

10. Fodde R, Smits R and Clevers H: Apc signal transduction and genetic instability in colon cancer. Nat Rev Cancer 1: 55-67, 2001.

11. Moser AR, Pitot HC and Dove WF: A dominant mutation that predisposes to multiple intestinal neoplasia in mouse. Science 247: 322-324, 1990.

12. Su L-K, Kinzler KW, Vogelstein B, et al: Multiple intestinal neoplasia caused by a mutation in the murine homolog of the APC gene. Science 256: 668-670, 1992.
13. Katdare M, Kopelovich L and Telang N: Efficacy of chemopreventive agents on growth inhibition of Apc [+/-] 1638NCOL colonic epithelial cells. Int J Mol Med 10: 427-432, 2002.

14. Telang $\mathrm{N}$ and Katdare M: Combinatorial prevention of carcinogenic risk in a model for familial colon cancer. Oncol Rep 17: 909-914, 2007.

15. Telang NT, Li G and Katdare M: Prevention of early onset familial/hereditary colon cancer: new models and mechanistic biomarkers (Review). Int J Oncol 28: 1523-1529, 2006.

16. Telang NT, Osborne MP, Sweterlitsch LA, et al: Neoplastic transformation of mouse mammary epithelial cells by deregulated myc expression. Cell Regulation 1: 863-872, 1990.

17. Rao CV, Yang YM, Swamy MV, et al: Colonic tumorigenesis in Bub R1[+/-]/Apc $\mathrm{Ain}^{+}+$compound mutant mice is linked to premature separation of sister chromatid and enhanced genomic instability. Proc Natl Acad Sci USA 102: 4365-4370, 2005.

18. Sodir NM, Chen X, Park R, et al: Smad-3 deficiency promotes tumorigenesis in the distal colon of $\mathrm{Apc}^{\mathrm{Min}} /+$ mice. Cancer Res 66: 8430-8438, 2006

19. Cho NL, Javid SH, Carothers AM, et al: Estrogen receptors o and $B$ are inhibitory modifiers of Apc dependent tumorigenesis in the proximal colon of Min/+ mice. Cancer Res 67: 2366-2372, 2007.

20. Fijneman R, De Wit H, Pourghiasian M, et al: Identification of mouse colon tumor secretome as putatyive biomarker for bloodbased screening of colorectal cancer. Cell Oncol 30: 156, 2008.

21. Yang K, Popova NV, Yang WC, et al: Interaction of Muc2 and Apc on wnt signaling and intestinal tumorigenesis: potential role of chronic inflammation. Cancer Res 68: 7313-7322, 2008.

22. Telang NT, Narayanan R, Bradlow HL, et al: Co-ordinated expression of intermediate biomarkers for tumorigenic transformation of Ras transfected mouse mammary epithelial cells. Breast Cancer Res Treat 18: 155-163, 1991.

23. Telang $\mathrm{N}$ and Katdare $\mathrm{M}$ : Cell culture model for colon cancer prevention and therapy: an alternative approach to animal experimentation. ALTEX 24: 16-21, 2007.

24. Massague J, Blain SW and Lo RS: TGF- $\beta$ signaling in growth control, cancer and heritable disorders. Cell 103: 295-309, 2000.

25. Woodburn JR: The epidermal growth factor receptor and its inhibition in cancer therapy. Pharmacol Ther 82: 241-250, 1999.

26. Singh M and Johnson L: Using genetically engineered mouse models of cancer to aid drug development: an industry perspective. Clin Cancer Res 12: 5312-5328, 2006.

27. Frese KK and Tuveson DA: Maximizing mouse cancer models. Nat Rev Cancer 7: 645-658, 2007.

28. Abate-Shen C, Brown PH, Colburn NH, et al: The un-trapped potential of genetically engineered mouse models in chemoprevention research: opportunities and challenges. Cancer Prev Res 1: 161-166, 2008.

29. Bresalier RS, Sandler RS, Quan H, et al: Cardio-vascular events associated with Rofecoxib in a colorectal adenoma chemoprevention trial. N Engl J Med 352: 1092-1102, 2005.

30. Gerner EW and Meyskens F: Polyamines and cancer: old molecules, new understanding. Nat Rev Cancer 4: 785-792, 2004.

31. Giardiello FM, Hamilton SR, Hylind M, et al: Ornithine decarboxylase and polyamines in familial adenomatous polyposis. Cancer Res 57: 199-201, 1997.

32. Solomon SD, McMurray JJV, Pfeffer M, et al: Cardiovascular risk associated with Celecoxib in a clinical trial for colorectal adenoma prevention. N Engl J Med 352: 1071-1080, 2005.

33. Swamy MV, Cooma I, Jagan MR, et al: Modulation of Cox-2 activity by the combined action of celecoxib and docosa hexaenoic acid: novel strategy for prevention and treatment. Mol Cancer Ther 3: 215-223, 2004

34. Meyskens FL, McLaren CE, Petot D, et al: Difluoro methylornithine plus sulindac for the prevention of sporadic colorectal adenomas: a randomized placebo controled, double-blind trial. Cancer Prev Res 1: 32-38, 2008.

35. Sarkar FH and Li Y: Using chemopreventive agents to enhance the efficacy of cancer chemotherapy. Cancer Res 66: 3347-3350, 2006.

36. Ju J, Hong J, Zhu N, et al: Inhibition of intestinal tumorigenesis in $\mathrm{Apc}^{\mathrm{Min} /+}$ mice by (-)-Epigallocatechin-3-gallate, the major catechin in green tea. Cancer Res 65: 10623-10631, 2005.

37. Nagel R, La Sage C, Diosdado B, et al: Regulation of the adenomatous polyposis coli gene by the miR-135 family in colorectal cancer. Cancer Res 68: 5795-5812, 2008. 